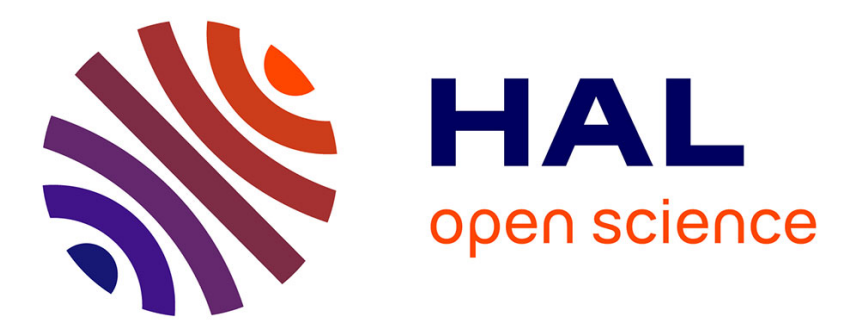

\title{
Protected Light-Trapping Silicon by a Simple Structuring Process for Sunlight-Assisted Water Splitting
}

L. Santinacci, M.W. Diouf, M.K.S. Barr, Bruno Fabre, L. Joanny, F. Gouttefangeas, Gabriel Loget

\section{To cite this version:}

L. Santinacci, M.W. Diouf, M.K.S. Barr, Bruno Fabre, L. Joanny, et al.. Protected Light-Trapping Silicon by a Simple Structuring Process for Sunlight-Assisted Water Splitting. ACS Applied Materials \& Interfaces, 2016, 8 (37), pp.24810-24818. 10.1021/acsami.6b07350 . hal-01381130

\section{HAL Id: hal-01381130 https://hal-univ-rennes1.archives-ouvertes.fr/hal-01381130}

Submitted on 9 Mar 2021

HAL is a multi-disciplinary open access archive for the deposit and dissemination of scientific research documents, whether they are published or not. The documents may come from teaching and research institutions in France or abroad, or from public or private research centers.
L'archive ouverte pluridisciplinaire HAL, est destinée au dépôt et à la diffusion de documents scientifiques de niveau recherche, publiés ou non, émanant des établissements d'enseignement et de recherche français ou étrangers, des laboratoires publics ou privés. 


\section{Protected Light-Trapping Silicon Structured by a Simple Process for Sunlight-assisted Water Splitting}

Lionel Santinacci, ${ }^{\ddagger *} *$ Mä̈mouna W. Diouf, ${ }^{\ddagger}$ Maïssa K. S. Barr ${ }^{\ddagger}$ Bruno Fabre, ${ }^{\dagger}$ Loüc Joanny ${ }^{\S}$

Francis Gouttefangeas ${ }^{\S}$ Gabriel Loget ${ }^{\dagger} *$

$\dagger$ Institut des Sciences Chimiques de Rennes, UMR 6226 CNRS, Matière Condensée et

Systèmes Electroactifs (MaCSE), Université de Rennes 1, Campus de Beaulieu, 35042 Rennes

Cedex, France.

† Aix Marseille Université, CNRS, CINaM UMR 7325, 13288, Marseille, France.

$\S$ ScanMAT - CMEBA, Université de Rennes 1, Campus de Beaulieu, 35042 Rennes Cedex,

France.

KEYWORDS

Black Silicon, Electrochemical Etching, Atomic Layer Deposition, Nanostructuration,

Photoanode, Water Splitting, Photoelectrochemical Cells

ABSTRACT. Macroporous layers are grown onto $n$-type silicon by successive photoelectrochemical etching in HF containing solution and chemical etching in $\mathrm{KOH}$. This specific latter treatment gives highly antireflective properties of the Si surface. The duration of the chemical etching is optimized to render the surface as absorbent as possible and the morphology of the as-grown layer is characterized by scanning electron microscopy. Further functionalization of such structured Si surface is carried out by atomic layer deposition of a thin conformal and homogenous $\mathrm{TiO}_{2}$ layer that is crystallized by an annealing at $450^{\circ} \mathrm{C}$. This process allows using such surfaces as photoanodes for water oxidation. The $40 \mathrm{~nm}$-thick $\mathrm{TiO}_{2}$ film acts 
indeed as an efficient protective layer against the photocorrosion of the porous $\mathrm{Si}$ in $\mathrm{KOH}$, enhances its wettability and enlarge the light absorption of the photoelectrode. The macroporous Si has a beneficial effect on water oxidation in $1 \mathrm{M} \mathrm{KOH}$ and leads to a considerable negative shift of onset potential of $\sim 400 \mathrm{mV}$ as well as a $50 \%$ increase in photocurrent at $1 \mathrm{~V}$ vs SCE.

\section{INTRODUCTION}

The conversion of sunlight into storable and transportable chemical fuels, that can be used for generating electricity, is a very appealing alternative to batteries and could be highly beneficial to circumvent the intermittency of renewable sources of energy. ${ }^{1}$ In this context, the development of photoelectrochemical cells (PECs) allowing the splitting of water for producing $\mathrm{H}_{2}$ and $\mathrm{O}_{2}$ at high rates is a very active field of research..$^{2-4}$ PECs are generally based on semiconductor electrodes, immersed in an aqueous electrolyte, that can use the sunlight to drive electrochemical reactions such as water oxidation and reduction..$^{5-8}$ Among all the semiconductors that have been studied for PECs, silicon is currently attracting a tremendous scientific interest for application in water splitting for several reasons. ${ }^{9}$ First, it is the second most abundant element in the earth's crust and therefore it is relatively cheap. Second, it exhibits a suitable electronic structure with well-positioned band edges and a narrow bad gap of $1.1 \mathrm{eV}$, which is particularly adapted to the solar spectrum. However, Si suffers from two main drawbacks which are: its instability in aqueous media and its high reflectance. This first issue is crucial when $\mathrm{Si}$ is used as a photoanode because in this case photocorrosion leads to the passivation of the $\mathrm{Si}$ with an insulating $\mathrm{SiO}_{\mathrm{x}}$ layer and therefore induces its deactivation. Nevertheless, this stability issue can be solved by appropriate protection of the surface. In particular, it has been shown that Si photoanodes can be highly stable in the harsh conditions required for splitting water when protected with thin layers 
grown by physical vapor deposition (PVD), ${ }^{10}$ by atomic layer deposition (ALD) $)^{11-18}$ or electrodeposition. ${ }^{19,20}$ The main optical loss at the Si surface is caused by the high Fresnel reflection of solar light by planar Si, which avoids the absorption of a large part of incident photons that cannot generate electron-hole pairs. This problem has triggered a strong interest in developing light management strategies to increase photon absorption and therefore to improve the Si-based PEC efficiencies. ${ }^{9,21,22}$ In this context, micro- and nanostructuration of Si surfaces are efficient approaches for effectively decreasing the reflectivity of crystalline Si and, at the same time, increasing the surface area while keeping the electronic properties of bulk $\mathrm{Si} .^{9,21,22}$ The antireflective nature of structured Si surfaces arises either from a continuous gradient of refractive index or from multiple internal reflections, ${ }^{22}$ when the structures are respectively smaller or larger than the incident wavelength. Several processes have been reported for fabricating structured antireflective or "black" Si. Vapor deposition" ${ }^{21}$ and patterned wet, ${ }^{23,24}$ dry, ${ }^{25,26}$ or electrochemical etching ${ }^{27}$ have been used to prepare Si surfaces having very promising optical and electrochemical properties. Nevertheless, these processes require the use of relatively costly vacuum or lithographic equipment. Few cost-effective techniques can be used to fabricate antireflective Si. For instance, alkaline wet etching is commonly employed to prepare random micropyramid arrays. ${ }^{28}$ Alternatively, nano- and micro-scale structuration can be performed by simple processes such as metal-assisted chemical etching (MACE) or electrochemical etching on electronic or metallurgical grade $\mathrm{Si}^{29-32}$ Although these structures exhibit low reflectance, if their dimension is too small, it can lead to a low built-in field and a weak charge separation. ${ }^{33}$ In addition, those structures usually have high contact angles and narrow pore apertures, which may inhibit solvent penetration and optimal diffusion of ions within the pores. In this article, we report a rapid, inexpensive two-step method for structuring $n$-type $\mathrm{Si}$ (100) surfaces with micron- 
sized cavities. The process is based on the photoelectrochemical etching (PEE) of the Si surface and its subsequent alkaline etching. This method produces a layer of random macropores over a large area, which renders the Si surfaces antireflective over the visible spectrum. We demonstrate that such surfaces can be coated by $\mathrm{ALD}$ of $\mathrm{TiO}_{2}$ thin conformal layers and that they can be used as stable photoanodes producing enhanced photocurrents under simulated sunlight with respect to their planar counterparts.

\section{EXPERIMENTAL SECTION}

\section{Structuration and Characterization of Si Surfaces}

The $n$-type silicon (100) wafers (phosphorus doped, $1-5 \Omega \mathrm{cm}$, double side polished, Siltronix) were cut in $1.5 \times 1.5 \mathrm{~cm}^{2}$ squares and degreased by sonication (10 $\left.\mathrm{min}\right)$ in acetone (MOS electronic grade, Carlo Erba), ethanol (RSE electronic grade, Carlo Erba) and ultrapure water (resistivity: $18.2 \mathrm{M} \Omega \mathrm{cm}$ ). The surfaces were then cleaned in $3 / 1 \mathrm{v} / \mathrm{v}$ concentrated $\mathrm{H}_{2} \mathrm{SO}_{4}$ (MOS electronic grade, $\mathrm{BASF}) / 30 \% \mathrm{H}_{2} \mathrm{O}_{2}$ (VLSI electronic grade, Sigma-Aldrich) at $100^{\circ} \mathrm{C}$ for $30 \mathrm{~min}$, followed by copious rinsing with ultrapure water (Caution: The concentrated aqueous $\mathrm{H}_{2} \mathrm{SO}_{4} / \mathrm{H}_{2} \mathrm{O}_{2}$ (piranha) solution is very dangerous, particularly in contact with organic materials, and should be handled extremely carefully). The surfaces were etched in $5 / 1 \mathrm{v} / \mathrm{v}$ ultrapure water $/ 50 \%$ aq. HF (MOS electronic grade, Sigma-Aldrich) for $2 \mathrm{~min}$ in order to remove the oxide layer and were dried under an argon stream. For the photoelectrochemical etching, the surfaces were inserted into a home-made open-top O-ring cell (the diameter of the O-ring was 1 $\mathrm{cm})$. The electrical contact was achieved by pressing an aluminum foil at the back of the $\mathrm{Si}$ surface and the counter electrode was a Pt ring (diameter of $1 \mathrm{~cm}$ ) placed above the silicon surface. The cell was filled with $4 \mathrm{~mL}$ of electrolyte solution containing absolute ethanol (VWR) 
and $50 \%$ aq. $\mathrm{HF}$ at a $1 / 1 \mathrm{v} / \mathrm{v}$ ratio. The Si surface was irradiated with a solar simulator (LS0106, LOT Quantum Design) and a current of $40 \mathrm{~mA}$ was applied for $10 \mathrm{~min}$ with a power supply (LAB-SMP, ET System). The surface was then rinsed with absolute ethanol and dried under an argon flow. The electrochemically-etched samples were then directly exposed to a freshly prepared $1 \mathrm{M} \mathrm{KOH}$ (Sigma-Aldrich) aqueous solution containing $10 \%$ vol. ethanol for $10 \mathrm{~min}$. The surfaces were finally rinsed with absolute ethanol and dried under an Ar stream. Scanning electron microscopy (SEM) was performed using a JSM 7100F (JEOL) equipment. SEM picture analysis was performed using the ImageJ software for estimating the morphological parameters of the structured porous layers. Contact angle measurements were performed with an Easydrop measuring instrument (Krüss). Reflectance spectra were acquired on a Cary 100 (Varian) spectrophotometer, equipped with an integrating sphere (DRA-CA-301, Labsphere) referenced with a spectralon standard (Labsphere). The total reflectance was measured with the surface tilted to include the specular reflectance component; in contrast, the diffuse reflectance was measured without at a $0^{\circ}$ angle. The specular reflectance was obtained by subtracting the diffuse reflectance from the total reflectance.

\section{Atomic Layer Deposition, Annealing and Characterization of the $\mathrm{TiO}_{2}$ layers}

The $\mathrm{TiO}_{2}$ thin films were synthesized by atomic layer deposition in a Fiji 200 reactor from Ultratech/Cambridge NanoTech using titanium tetraisopropoxide (TTIP, 98\%, Strem chemicals) and ultrapure water (resistivity: $18.2 \mathrm{M} \Omega \mathrm{cm}$ ). The TTIP canister was maintained at $80^{\circ} \mathrm{C}$ while the temperature of the reaction chamber was set to $120^{\circ} \mathrm{C}$. The ALD cycle consisted of sequential pulse, exposure and purge of $\mathrm{Ti}$ precursor and $\mathrm{H}_{2} \mathrm{O}$, alternatively. The pulse, exposure and purge durations were 2:7:15 s and 0.2:7:15 s for TTIP and $\mathrm{H}_{2} \mathrm{O}$, respectively. The 
ALD of $\mathrm{TiO}_{2}$ was performed on both porous and flat $\mathrm{Si}$ substrates in order to facilitate some characterizations. The number of ALD cycles $(N)$ was varied in order to adjust the thickness of $\mathrm{TiO}_{2}$ layers. After the ALD of $\mathrm{TiO}_{2}$, the samples were annealed for 2 hours at $450^{\circ} \mathrm{C}$ in air to transform the amorphous layer to polycrystalline anatase. In addition to SEM, the interface between the macroporous $\mathrm{Si}$ and the $\mathrm{TiO}_{2}$ coatings was investigated by transmission electron microscopy (TEM) using a JEM 3010 (JEOL) TEM. The samples were cleaved into small pieces of $3 \times 2 \mathrm{~mm}^{2}$, polished and thinned by ion milling. Chemical analysis of the porous layers after ALD processes was carried out by energy dispersive X-ray spectroscopy (EDS) using a Xman detector (Oxford Instruments) mounted on Supra 40VP SEM (Zeiss). The crystal structures of the $\mathrm{TiO}_{2}$ layers were analyzed by X-ray diffraction (XRD) using a Rigaku RU-200 rotating anode X-ray generator (operating power $40 \mathrm{kV} / 30 \mathrm{~mA}$ ) equipped with a Xenocs Fox3D Cu 12_INF mirror and a Mar345 image plate detector from Rayonix. The thickness of the $\mathrm{TiO}_{2}$ thin layers on plane Si surfaces has been measured by spectroscopic ellipsometry using a M-2000V (J. A. Woollam Co.). The curve fitting was performed with the CompleteEase software applying a Tauc-Lorentz oscillator model. ${ }^{34}$

\section{Photoelectrochemical Measurements}

An ohmic contact was established on the backside of the $\mathrm{TiO}_{2}$-modified $\mathrm{Si}$ surface with a metal wire by first scrubbing the surface with sand paper and then applying InGa Eutectic (99.99\%, Alfa Aesar). A layer of silver paste (Electron Microscopy Sciences) was then deposited on the contact. After drying of the silver paste, the copper wire was inserted in a glass capillary and the electrode area $\left(0.3 \mathrm{~cm}^{2}\right)$ was defined with an epoxy-based resin (Loctite 9492 , Henkel), that covered all the back of the Si surface as well as the silver paste. The water oxidation experiments were performed in a home-made three neck cell in which were inserted a $\mathrm{KCl}$ saturated calomel 
reference electrode (SCE) and a Pt counter electrode. The cell was filled with a $1 \mathrm{M} \mathrm{KOH}$ solution that was deaerated by bubbling $\mathrm{Ar}$ for $20 \mathrm{~min}$ prior to experiments. $\mathrm{The}^{\mathrm{TiO}_{2}}$-modified Si surface, sealed in epoxy was disposed in front of a quartz window and was used as a working electrode. The light source was provided by a solar simulator (LS0106, LOT Quantum Design). Electrochemical measurements were performed with a potentiostat/galvanostat Autolab PGSTAT 302N (Eco Chemie BV). The cyclic voltammograms were recorded at $20 \mathrm{mV} / \mathrm{s}$.

\section{RESULTS AND DISCUSSION}

\section{Fabrication and morphological characterization of the macroporous Si surfaces}

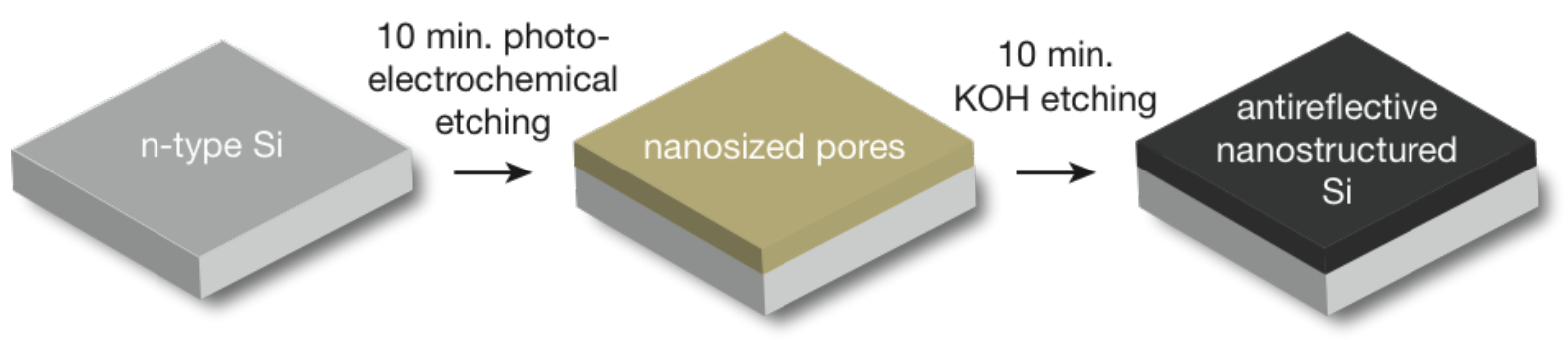

FIGURE 1. Scheme of the two-step process used for the fabrication of the antireflective macroporous silicon surfaces.

The two-step structuration process used in this work is described in Figure 1. First, a photoelectrochemical etching (PEE) was performed to pre-structure the Si surfaces. The $n$-Si surfaces were held at a constant anodic current $\left(50.9 \mathrm{~mA} \mathrm{~cm}{ }^{-2}\right)$, in an ethanol/ $\mathrm{HF}$ electrolyte for 10 min using a front side illumination. As shown in Figure 2a, the PEE step generated a $\sim 30 \mu \mathrm{m}$-thick layer of porous silicon (that was luminescent, as observed by naked eyes under $\lambda=365 \mathrm{~nm}$ irradiation) which consisted of a $13 \mu \mathrm{m}$-thick layer of a loosely-attached porous 
"crust" on the top of a dense layer of micro/mesoporous silicon (see Figure S1 in supporting information for a top view). Importantly, SEM observations reveal the presence of macropores at the bottom of the layer, that are typically filled with micro/mesopores ${ }^{35-37}$ In the second step, the pre-structured surface was readily chemically etched in an aqueous solution of $1 \mathrm{M} \mathrm{KOH}$ comprising $10 \%$ vol. of ethanol (to improve the penetration of the solution into the hydrophobic porous layer). $\mathrm{KOH}$ solutions are commonly used to etch Si according to the following reaction: ${ }^{38}$

$$
\mathrm{Si}+2 \mathrm{OH}^{-}+2 \mathrm{H}_{2} \mathrm{O} \rightarrow \mathrm{SiO}_{2}(\mathrm{OH})_{2}^{2-}+2 \mathrm{H}_{2}
$$

Due to the very high surface area of micro/mesoporous Si, this material etches at a much faster rate that bulk Si. Thanks to this, micro/mesoporous Si has been previously used as a sacrificial layer for MEMs fabrication ${ }^{39}$ and for transferring nanostructures on various substrates.$^{40}$
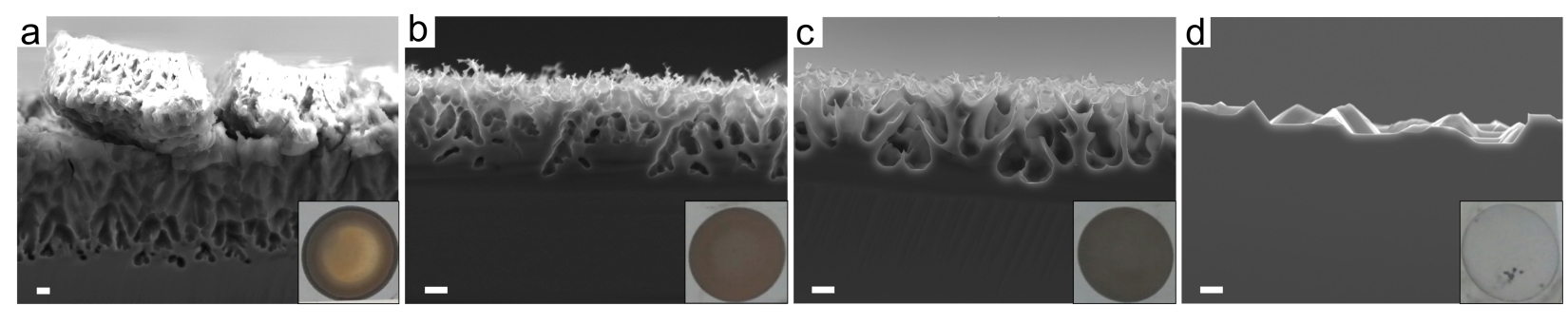

FIGURE 2. SEM pictures showing cross-sections of the porous Si surface submitted to different immersion times in $\mathrm{KOH}$ : a) $0 \mathrm{~min}$, b) $2 \mathrm{~min}$, c) $10 \mathrm{~min}$ and d) $60 \mathrm{~min}$. The scale bars are equal to 2 micrometers. Insets are photographs of the corresponding structured surfaces (the diameter of the structured Si discs equals $1 \mathrm{~cm}$ ).

In order to follow the evolution of the porous layer with respect to the etching time, surfaces prepared by PEE and immersed in $\mathrm{KOH}$ for different times were observed by SEM. The effect of 
the $\mathrm{KOH}$ etching time is shown in the series of cross-section images in Figure 2. As it can be seen in Figure 2b, the "crust" and the top nanoporous layer readily dissolved during the first minutes of etching, leading to open-top macropores (see Figure S1b for top view). This is totally consistent with a preferential etching of nanoporous $\mathrm{Si}$ with respect to bulk $\mathrm{Si},{ }^{41}$ and is confirmed by the observation of a higher bubble evolution rate during the first minutes of etching. This bubble evolution is caused by a high production of $\mathrm{H}_{2}$, as it can be seen in equation 1 . After 4 to $5 \mathrm{~min}$, the rate of bubble evolution clearly decreases suggesting that the whole micro/mesoporous layer was etched. However, after this period of time, $\mathrm{H}_{2}$ evolution does not stop but proceed at a slower rate, suggesting that the etching of bulk silicon takes place.

Figure 2c shows that 10 min of etching produced larger cavities with wider apertures (the top view is shown in Figure S1c). For extended etching times, $e . g .1 \mathrm{~h}$, the macroporosity disappeared and low aspect ratio microwells could be observed on the surface (Figures $2 \mathrm{~d}$ and S1d). To summarize, the morphological evolution shown in Figure 2 can be easily understood by the preferential etching of the nanostructured $\mathrm{Si}$ on the porous layer that quickly dissolved and led to a random template of macropores (Figure $2 \mathrm{~b}$ ). The further etching of this template induced a widening of the cavities (Figure 2c) that leads in fine the removal of the pore walls (Figure 2d).

Interestingly, the surfaces exhibited a clear color evolution during the etching process, which can be observed in the insets of Figure 2a-d showing photographs of the dried surfaces. While the PEE surface is initially dark-yellow, it becomes brown after 2 min of alkaline etching and matte black after $10 \mathrm{~min}$. The final removal of the macroporous layer, obtained after $1 \mathrm{~h}$ of etching leads to the loss of the light-trapping properties and a gray color. SEM observations revealed the absence of micro/mesopores, which was further confirmed by the disappearance of the photoluminescence for the $\mathrm{KOH}$-etched samples (as observed by naked eyes under a $\lambda=365 \mathrm{~nm}$ 
irradiation). As the darkest color and the widest pores are obtained for an etching time of $10 \mathrm{~min}$, this treatment duration has been used for all the following experiments.

Morphological characterization of the so-fabricated samples was performed by SEM analysis. Figure 3 shows some images of a typical structured Si surface. This figure reveals clearly the presence of a high density of macropores, randomly distributed on the silicon substrate. Measurements performed on several surfaces allowed to determine a layer thickness of $4.9 \pm 1.4 \mu \mathrm{m}$ (Figure 3a). The SEM picture of Figure $3 \mathrm{~b}$ shows the presence of single pores but also branched pores connected by the same aperture. This image allows us to estimate a pore density of $\sim 2 \times 10^{5} \mathrm{~mm}^{-2}$ and a size of aperture in the micrometer range. 


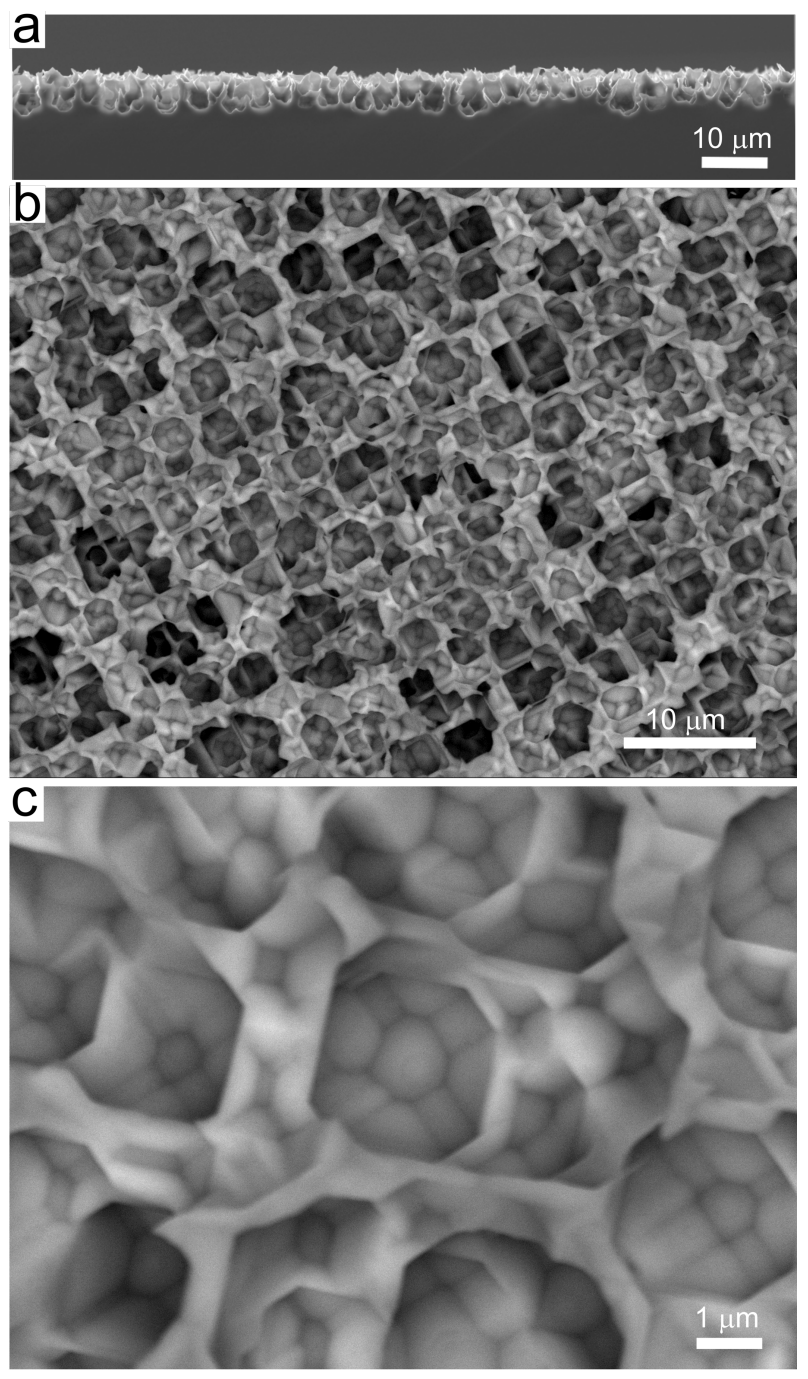

FIGURE 3. SEM pictures showing a) the cross-section, b) a low magnification top view and c) a high magnification top view of the macroporous Si structure obtained by the process shown in Figure 1 (etching time of $10 \mathrm{~min}$ ).

Although the pore distribution and dimensions are rather regular over the majority of the etched surface, we noticed a decrease in the thickness and aperture size at the border of the etched disc that is attributed to the uneven distribution of the electric field at the edge of the surface during PEE. High-magnification SEM top view reveals some interesting features of the pores. In 
particular, Figure 3c shows that their bottom comprised (100), (101), (110) and (111) exposed facets, which is a result of the well-known anisotropic etching of Si by $\mathrm{KOH}^{42}$

\section{Deposition and Characterization of the $\mathrm{TiO}_{2}$-Protective Layers.}

The structured $\mathrm{Si}$ surfaces were then coated with a conformal layer of $\mathrm{TiO}_{2}$ using atomic layer deposition, which is known to efficiently protect silicon photoanodes in alkaline

electrolytes. ${ }^{14,15,43}$ The deposition proceeds according to the expected ALD process that was first proposed by Ritala et al. ${ }^{44}$ The thickness evolution has been monitored by ex situ spectroscopic ellipsometry (supporting information, Figure S2). It reveals a linear increase from which the growth per cycle (GPC) of $0.28 \AA$ /cycle is deduced. This is slightly higher than initial reports using TTIP ${ }^{44,45}$ but it is in line with recent works. ${ }^{34}$ It is then closer to the GPCs of 0.4 and $0.8 \AA$ /cycle measured when the deposition is carried out with $\mathrm{TiCl}_{4}$ or tetrakis(dimethylamino)titanium (TDMAT), respectively. ${ }^{46,47}$

The silicon $/ \mathrm{TiO}_{2}$ interface was characterized by SEM as shown in Figure 4. The two pictures reveal that the $\mathrm{TiO}_{2}$ film is highly conformal and rather homogeneous with a layer thickness ranging from 37 to $41 \mathrm{~nm}$, both on the bottom (Figure 4a) or at the top of the pores (Figure 4b). It validates the thickness evaluation performed by spectroscopic ellipsometry. The film looks relatively smooth and fully covers the porous structures. The SEM images also clearly show the faceting of the macroporous layer induced by $\mathrm{KOH}$ treatment that has been mentioned before. 

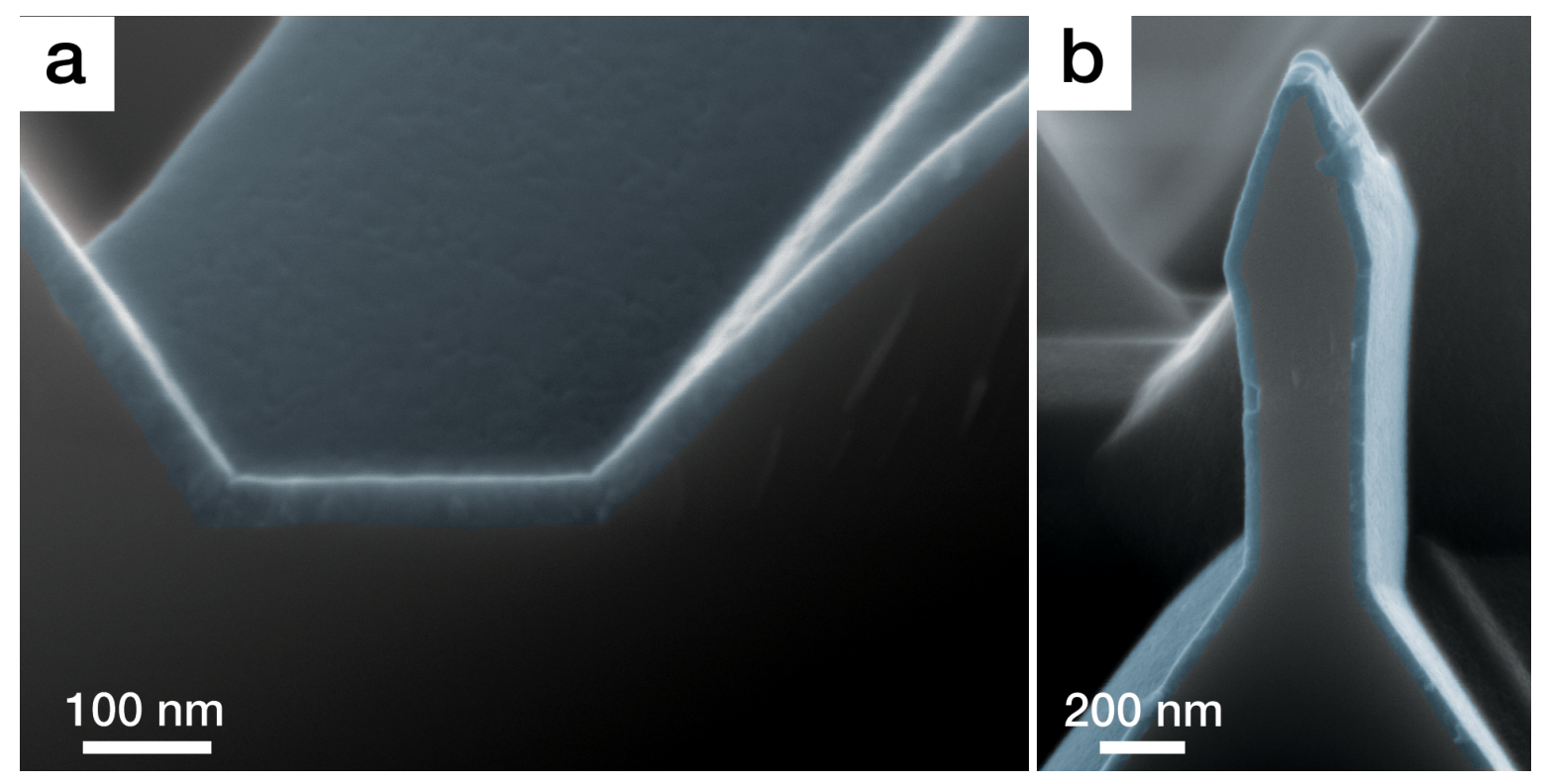

FIGURE 4. Cross-section SEM pictures showing a) the bottom and b) the top parts of the porous layer after ALD of $\mathrm{TiO}_{2}(N=1400$ cycles $)$. For clarity reasons, the $\mathrm{TiO}_{2}$ layer was colored in blue.

Chemical analysis of the samples has been performed by EDX. The spectrum (shown in supporting information, Figure S3) confirms the presence of $\mathrm{TiO}_{2}$ on the surfaces, revealed by the respective $\mathrm{Ti} \mathrm{K} \alpha$, Ti $\mathrm{K} \beta$ and $\mathrm{O} \mathrm{K} \alpha$ peaks at $4.5,4.9$ and $0.5 \mathrm{keV}$. Interestingly, the surfaces also contained detectable amounts of $\mathrm{K}$ and $\mathrm{C}$. It is, therefore, supposed that the incorporation of the first element originated from the etching in $\mathrm{KOH}$ while the presence of carbon is attributed either to the incorporation of organics during the ALD process, which has already been reported using TTIP as a precursor ${ }^{47}$ or to a plausible carbon contamination in the SEM. Additionally, EDX mapping for $\mathrm{Si}, \mathrm{Ti}$, and $\mathrm{O}$ on a cross-section is shown in Figure 5. It confirms the presence of conformal titania and reveals that the $\mathrm{TiO}_{2}$ layer is located evenly in the porous layer. It is, indeed, observed that while $\mathrm{Si}$ could be detected on the whole surface, $\mathrm{Ti}$ and $\mathrm{O}$ are mostly present in the porous layer. As expected, the Si concentration is found constant for the "bulk" 
silicon and decreased in the porous area due to the lower density of this material. Conversely, almost no Ti and $\mathrm{O}$ are detected on the bulk part but increased considerably in the porous layer, confirming that $\mathrm{TiO}_{2}$ was deposited on the whole porous layer.
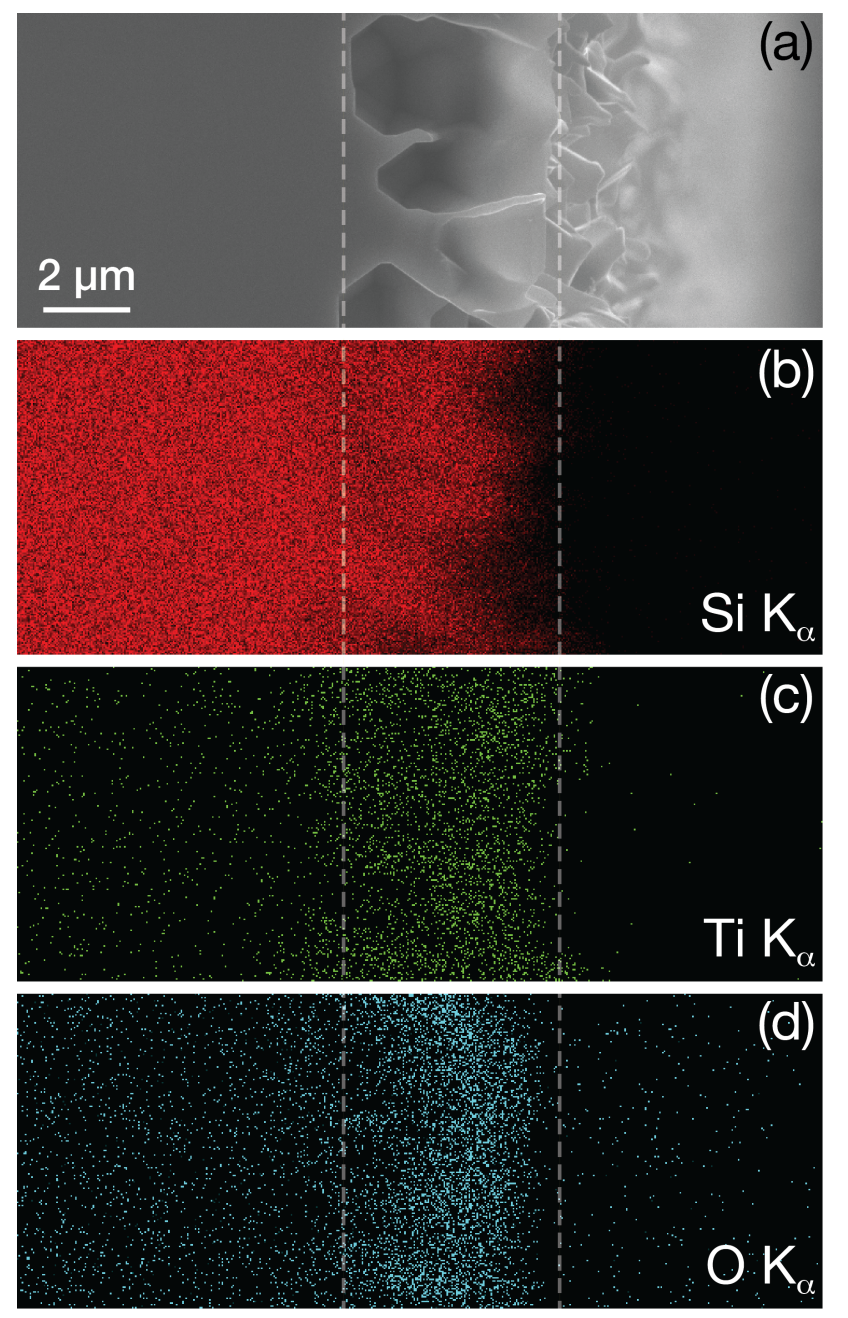

FIGURE 5. a) SEM cross section of a porous $\mathrm{Si}$ layer after $\mathrm{ALD}$ of $\mathrm{TiO}_{2}(N=1400$ cycles $)$ and corresponding EDX mapping of the same area for b) $\mathrm{Si} \mathrm{K} \alpha$, c) Ti K $\alpha$ and d) $\mathrm{O}$ K $\alpha$ peaks. 


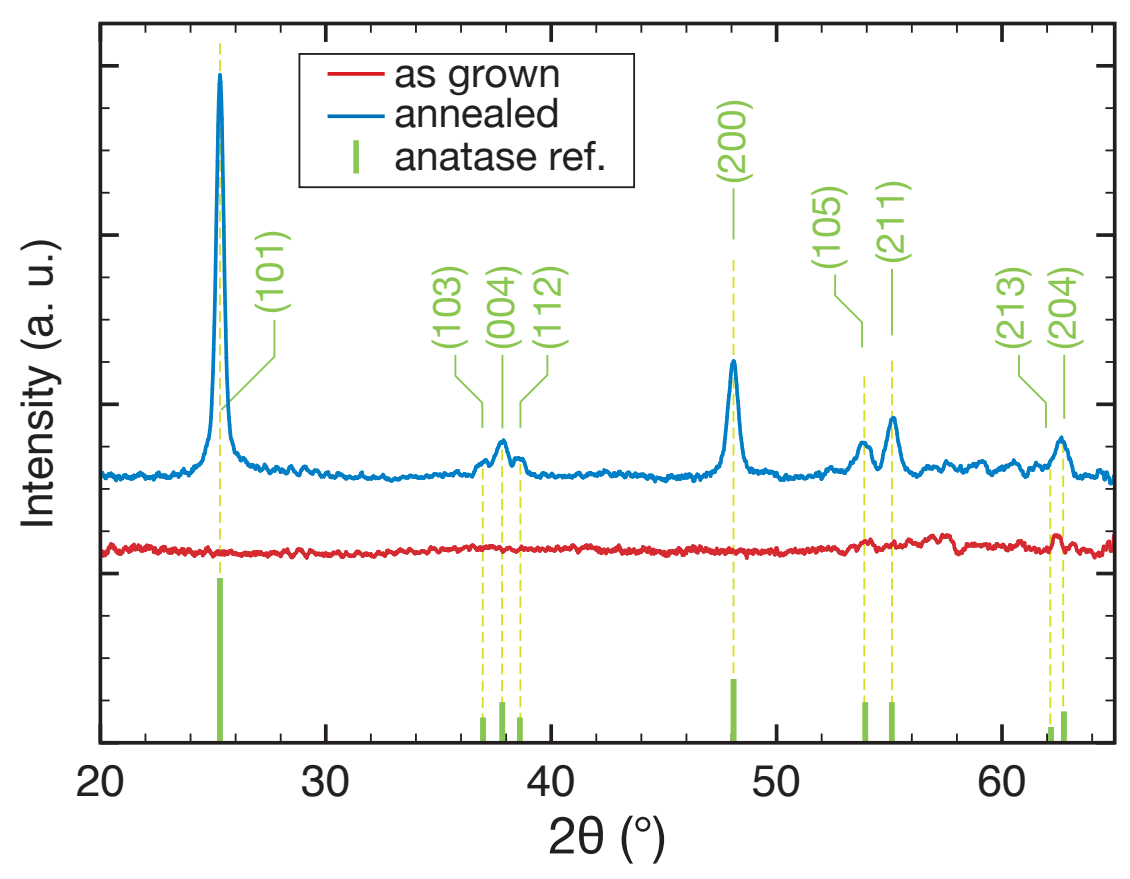

FIGURE 6. XRD diagrams of a porous silicon surface after deposition of $\mathrm{TiO}_{2}$ by ALD (red) and after thermal annealing at $450^{\circ} \mathrm{C}$ in air for $2 \mathrm{~h}$ (blue). The green lines represent the position of the $\mathrm{TiO}_{2}$ anatase peaks (JCPDS \# 00-021-1271).

After the coating, the surfaces were annealed in air at $450^{\circ} \mathrm{C}$ for $2 \mathrm{~h} . \mathrm{XRD}$ analyses performed before and after the thermal treatment are shown in Figure 6. The absence of diffraction peaks on the sample analyzed directly after ALD suggests that the as-grown films were amorphous. Note that the $\mathrm{Si}(100)$ peak originating from the substrate is not visible on the XRD diagram because it is out of the scanned angle range. Inversely, the characteristic diffraction peaks of anatase clearly appear after annealing. It indicates that the thermal treatment effectively crystallized the $\mathrm{TiO}_{2}$ thin film. This was already observed on flat Si after annealing at slightly higher temperatures. ${ }^{48}$ No peak related to the rutile phase is observed, which is desirable since anatase exhibits superior electronic properties. ${ }^{49}$ 
TEM imaging, shown in Figure 7a, clearly shows the sharp interface between the substrate and the deposit. The presence of a $\sim 3 \mathrm{~nm}$ thick amorphous $\mathrm{SiO}_{2}$ layer between the $\mathrm{TiO}_{2}$ and the $\mathrm{Si}$ can be easily noticed, which was likely formed during the first hydrolysis cycles of ALD. Crystalline rows are visible on the TEM image. It confirms the polycrystalline nature of $\mathrm{TiO}_{2}$ layer when it has been annealed. The selected-area electron diffraction (SAED) pattern presented in Figure $7 \mathrm{~b}$ displays the typical spots corresponding to the single-crystalline anatase phase. It indicates that though the $\mathrm{TiO}_{2}$ layer is polycrystalline, the crystallite size is in the range of the film thickness (i. e. 20 to $40 \mathrm{~nm}$ ). These findings are in line with the previous observations reported by MacDowell et al. ${ }^{48}$ for $\mathrm{TiO}_{2}$ films grown onto plane Si from TTIP.
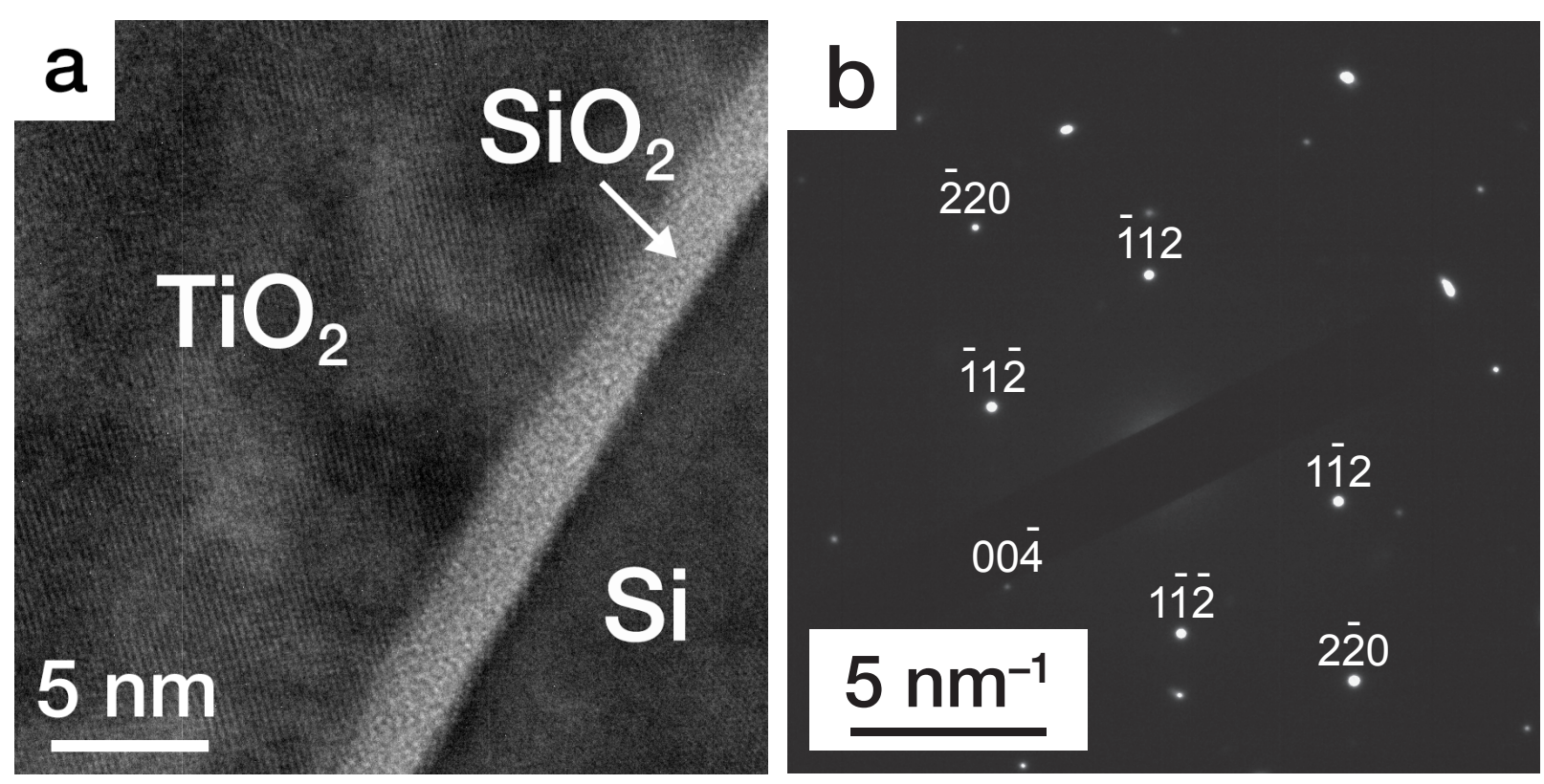

FIGURE 7. a) TEM cross section view of the $\mathrm{TiO}_{2} / \mathrm{Si}$ interface after annealing in air at $450^{\circ} \mathrm{C}$ for $2 \mathrm{~h}$ and $\mathrm{b}$ ) SAED of $\mathrm{TiO}_{2}$ layer.

\section{Contact angles and optical properties}

After the characterization of the morphology and the composition of the bare and the $\mathrm{TiO}_{2}$-protected porous silicon surfaces, their physicochemical properties such as their wettability 
and reflectivity are now discussed. Those parameters are crucial for application in the field of photoelectrochemical water splitting. The wettability of the Si surfaces has been investigated by contact angle measurements, performed directly after each surface treatment, as shown in Figure 8. First, hydrogenated flat $\mathrm{Si}$, exhibits a contact angle of $86^{\circ}$, which is fully consistent with data from the literature ${ }^{50}$ After PEE, the contact angle increases considerably to $142^{\circ}$, revealing the high hydrophobicity of the micro/mesoporous layer. This value evidences that such small pores on Si surfaces inhibit a good permeability of the structure, which is a significant matter for the targeted application. After alkaline etching, the value decreases to $96^{\circ}$, showing that the larger pores considerably improved the wettability. Such a contact angle value can be explained by the change in surface roughness. Nevertheless, FTIR data of the surface after structuration (supporting information, Figure S4) reveals the presence of $\mathrm{Si}-\mathrm{H}$ but also $\mathrm{Si}-\mathrm{O}$ bonds, suggesting that the surfaces were partially oxidized after structuring, which probably have a non-negligible influence on the contact angle value. These data demonstrate that the contact angle of the macroporous samples is considerably lower than the ones obtained for nanostructured $\mathrm{Si}$ such as nanoporous $\mathrm{Si}\left(142^{\circ}\right)$ or the ones typically reported for $\mathrm{Si}$ nanowire arrays $\left(\sim 130^{\circ}\right),{ }^{51}$ sometimes used as photoelectrodes in water. Finally, the contact angle measurements performed on the structured samples protected with the annealed $\mathrm{TiO}_{2}$ layer show that the coverage of the hydrophobic $\mathrm{Si}-\mathrm{H}$ moieties by the hydrophilic $\mathrm{TiO}_{2}$ film considerably increases the wettability which results in a value of contact angle of $26^{\circ}$. 


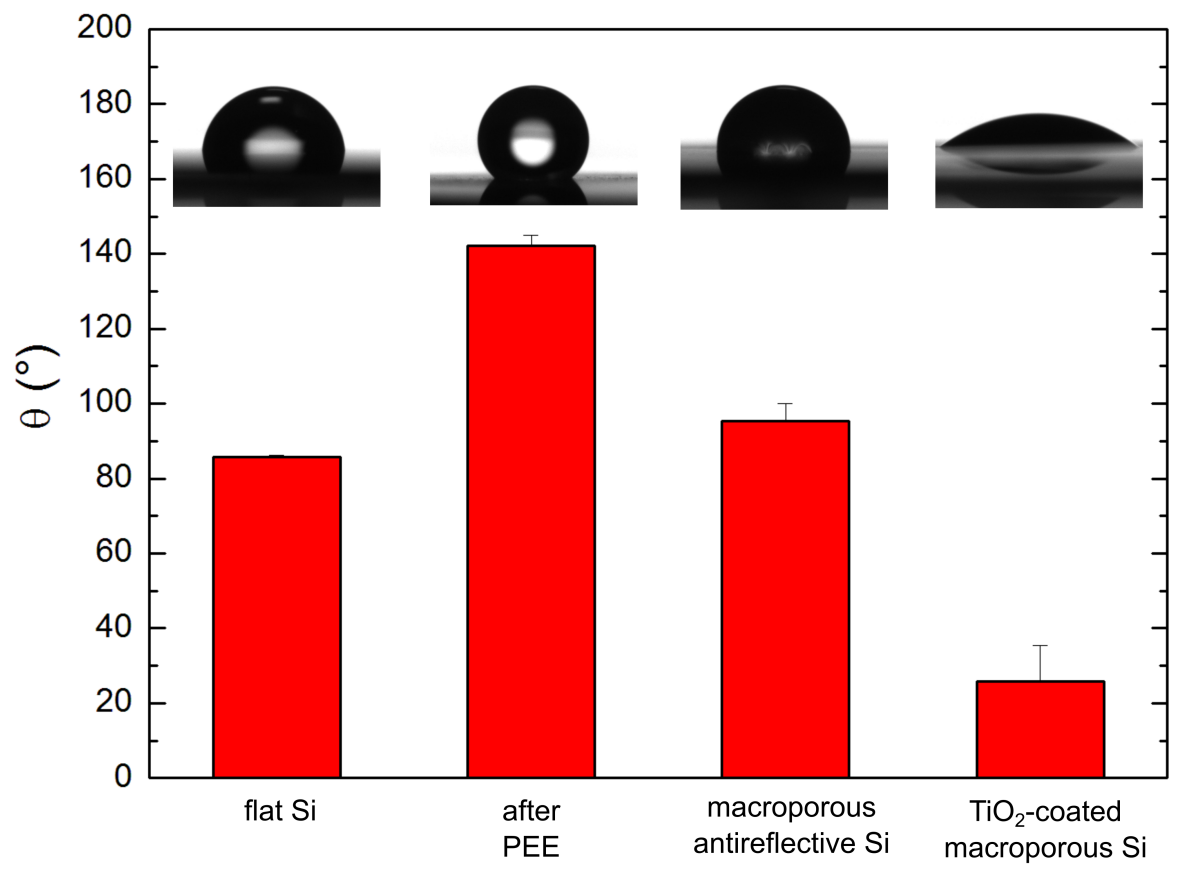

FIGURE 8. Evolution of the contact angle as a function of the structuration of the surface. Insets are representative photographs of a water droplet on the corresponding surface.

As previously discussed and shown in the insets of Figure 2, the structured surfaces clearly exhibit color changes during their structuring and the resulting macroporous surfaces are matte black, which demonstrates their light trapping properties. In order to gain precise insights on their optical characteristics, reflectance measurements have been performed with flat, bare macroporous and anatase $\mathrm{TiO}_{2}$-coated macroporous $\mathrm{Si}$ surfaces. Whereas the flat $\mathrm{Si}$ surface shows a total reflectance comprised between $95 \%$ and $43 \%$, reflectance for the bare structured surface is comprised between $34 \%$ and $18 \%$ (Figure 9). The reflectance of structured Si is therefore decreased by $\sim 60 \%$, which proves the significant effect of the Si structuring on the light absorption. Such a decrease in reflectance is in the same range than that previously reported for microstructured arrays comprising micropyramids ${ }^{28}$ or inverted micropyramid arrays. ${ }^{52}$ This 
data clearly demonstrate the light trapping properties of the macroporous surfaces, induced by multiple internal reflections of the incident light. Measurements of the diffuse reflectance allow extracting the specular component, shown in supporting information (Figure S5). These data indicate that the main reflection contribution is due to scattering of incident light at the rough interface, which induced a large diffuse reflectance $(\sim 85 \%$ of the total reflectance signal). In contrast, the specular reflection is found very low ( $<5 \%$, Figure S5). Finally, the $\mathrm{TiO}_{2}$ thin film has a beneficial effect on light absorption, and decreases the total reflectance by $\sim 22 \%$ with respect to the bare microstructured surface (Figure 9). This effect is thought to be ascribed to destructive optical interferences caused by the light reflection at the air/ $/ \mathrm{TiO}_{2}$ and $\mathrm{TiO}_{2} / \mathrm{Si}$ interfaces.

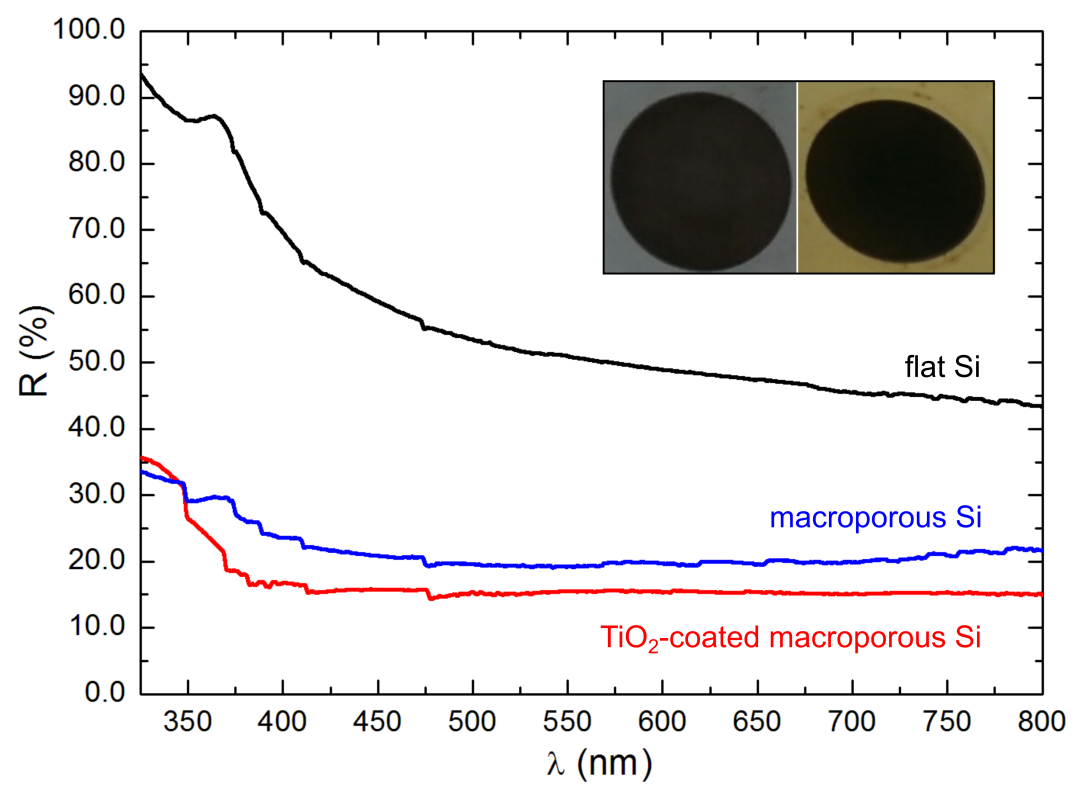

FIGURE 9. Total reflectance spectra obtained for planar Si (black), bare macroporous $\mathrm{Si}$ (blue) and $\mathrm{TiO}_{2}$-coated macroporous $\mathrm{Si}$ (red). Inset: photographs of the bare macroporous $\mathrm{Si}$ (left) and the $\mathrm{TiO}_{2}$-coated macroporous $\mathrm{Si}$ (right) (the diameter of the structured $\mathrm{Si}$ discs equals $1 \mathrm{~cm}$ ). 
Taken together, the present results prove that $\mathrm{TiO}_{2}$-protected macroporous surfaces have a good wettability and high optical absorption with respect to flat Si surfaces. Additionally, no etching of the $\mathrm{TiO}_{2}$ layer and the $\mathrm{Si}$ is observed upon immersion of these surfaces in a $1 \mathrm{M} \mathrm{KOH}$ solution, which highlights the protecting effect of the shell layer towards Si oxidation and motivates the use of these surfaces as photoanodes for water oxidation.

\section{Photoassisted-Oxidation of water}

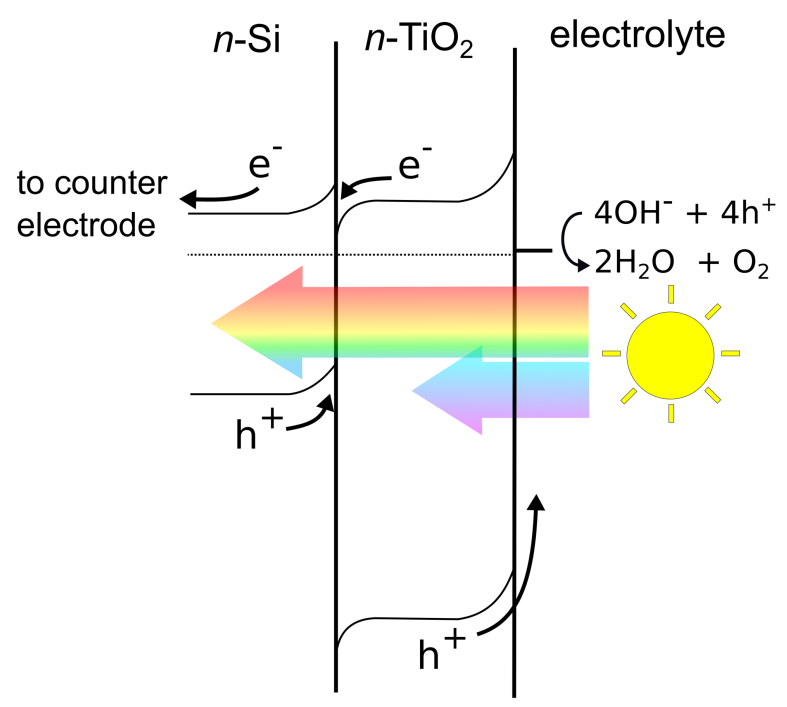

FIGURE 10. Scheme depicting the band diagram for water oxidation on an irradiated $\mathrm{TiO}_{2}$-coated $n$-Si surface.

The use of structured $n$-type $\mathrm{Si}$ surfaces protected by $\mathrm{TiO}_{2}$ layers having thicknesses of few tenths of nanometers for water oxidation has been first reported by Yang $e t$ al. ${ }^{11}$ and more recently by Wang et al. ${ }^{53}$, Ao et al. ${ }^{13}$ and by Lewis $e t a l .{ }^{54}$, who all highlighted beneficial effects of using structured instead of planar Si surfaces. Therefore, the present structured surfaces have been tested as photoanodes in $1 \mathrm{M} \mathrm{KOH}$ solution. Under simulated sunlight, water splitting is 
expected to occur following the mechanism depicted in Figure $10 .{ }^{11,13}$ The UV irradiation absorbed by $\mathrm{TiO}_{2}$ induces the formation of holes in the valence band that have sufficient energy to oxidize hydroxide ions. The unabsorbed part of the incident light generates electrons in the $n$-Si conduction band that can reduce water at the counter electrode and holes from the $n$-Si valence band recombine at the $\mathrm{Si} / \mathrm{TiO}_{2}$ interface with electrons from the $\mathrm{TiO}_{2}$ conduction band. In addition to the stability caused by the $\mathrm{TiO}_{2}$ film, a beneficial effect of this interface is the rejection of holes towards the $\mathrm{TiO}_{2} /$ water interface for driving water oxidation. ${ }^{11,13}$ 

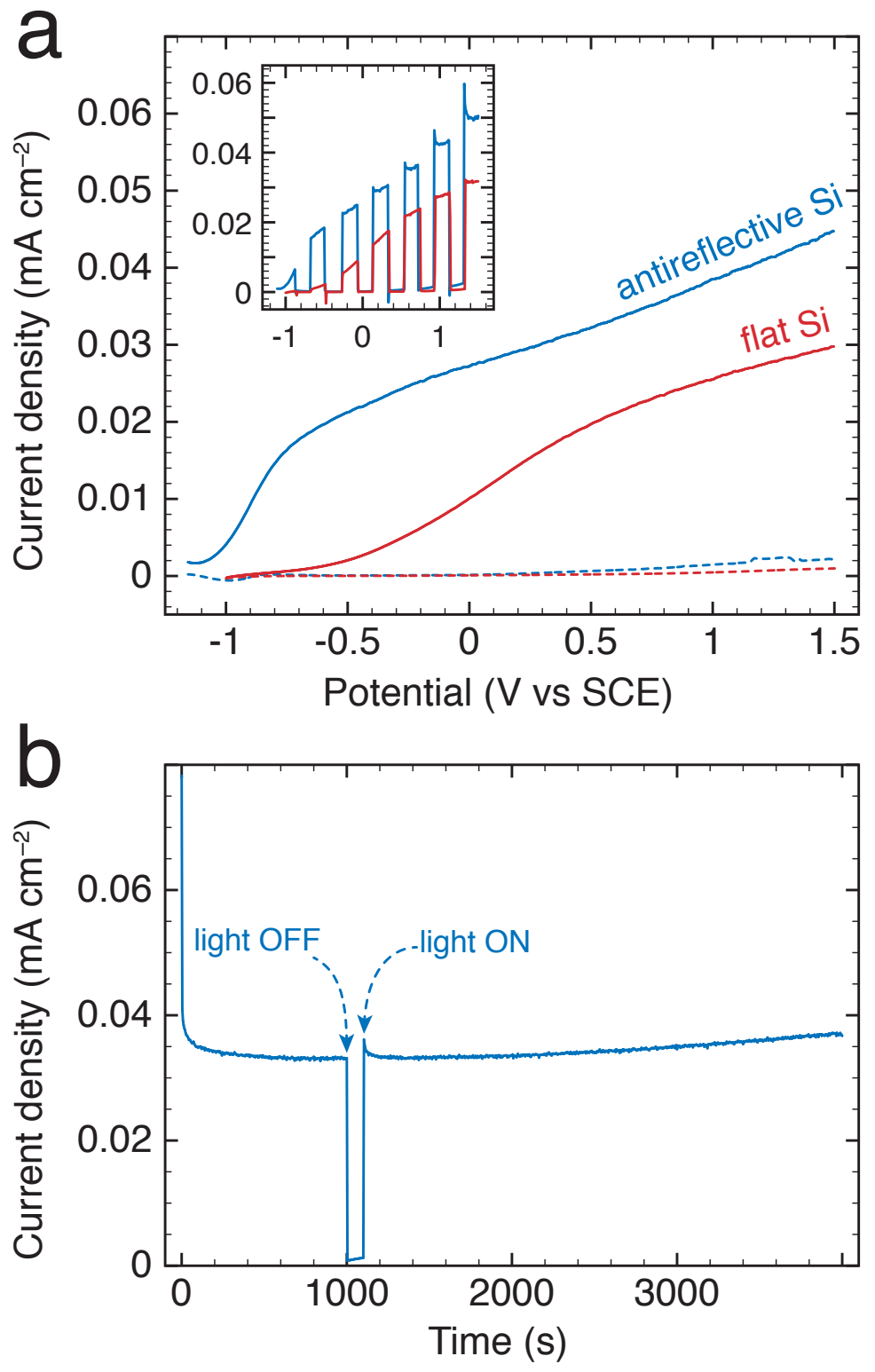

FIGURE 11. a) Linear sweep voltammograms in the dark (dashed lines) and under simulated sunlight irradiation (full lines) for the $\mathrm{TiO}_{2}$-coated flat $\mathrm{Si}$ (red) and $\mathrm{TiO}_{2}$-coated antireflective macroporous Si (blue) surfaces. Inset: voltammograms with chopped light. The sweep rate is $20 \mathrm{mV} \mathrm{s}^{-1}$. b) $J-t$ plot showing the photocurrent density obtained for the $\mathrm{TiO}_{2}$-coated macroporous Si surface at $1 \mathrm{~V}$ vs SCE during $4000 \mathrm{~s}$. All these curves were obtained in a $1 \mathrm{M} \mathrm{KOH}$ aqueous solution. 
The performances of the structured photoanodes, irradiated by simulated sunlight, are investigated and compared to a $\mathrm{TiO}_{2}$-coated flat $\mathrm{Si}$ surface using linear sweep voltammetry, as shown in Figure 11. In the dark, very low current densities, in the range of $1 \mu \mathrm{A} \mathrm{cm}^{-2}$, are obtained for both electrodes. In contrast, photocurrents in the range of 10 to $50 \mu \mathrm{A} \mathrm{cm}^{-2}$ are measured under illumination, indicating that water oxidation effectively occurs at both surfaces. The two curves have a very similar shape to the one previously reported ${ }^{11,13,53}$ but exhibit lower photocurrents. This can be attributed to the resistivity of our Si substrates. Shi et al. ${ }^{53}$ measured, indeed, photocurrents in the range of $1 \mathrm{~mA} \mathrm{~cm}^{-2}$ while the used Si substrates had a resistivity $10^{3}$ times lower $(0.001-0.005 \Omega \mathrm{cm})$. However, when the doping concentration was in the same range as that for the present substrates, the measured currents were found to be in the same range. ${ }^{11,13}$ Finally, McDowell et al. ${ }^{48}$ reported a much higher maximum current density but for a photoanode coated with an additional Ni layer that acted as a co-catalyst. Additionally, such differences may be a consequence of both differences in spectra of incident light and features of the deposited $\mathrm{TiO}_{2}$ layers, for instance, most previous reports used thicker $\mathrm{TiO}_{2}$ films. ${ }^{55,56}$

The curves show clearly that the macroporous silicon had a beneficial effect on water oxidation and led to a $50 \%$ increase in photocurrent at $1 \mathrm{~V}$ vs SCE. This rise is attributed to the improved absorption of photons in the porous matrix. In addition to this effect, the macroporous surface provided a higher active area that contributes to the photocurrent enhancement and also to the considerable negative shift of onset potential of $\sim 400 \mathrm{mV} \cdot .^{11,13}$ Although the surface structuring is generally expected to enhance the electron-hole recombination rate, the curves of Figure 11a clearly indicate that this effect is smaller than the gain obtained by the improved light absorption and the increased surface area. Another important benefit of the $\mathrm{TiO}_{2}$ coating is the 
stability that it provides to the Si matrix because silicon is usually highly prone to etch in this medium (vide supra). For instance, the etching of uncoated Si surfaces could be readily observed in this electrolyte by the appearance of $\mathrm{H}_{2}$ bubbles (see Eq. 1), which is not the case for the coated Si surfaces. The controlled-potential electrolysis performed at $1 \mathrm{~V}$ vs SCE, shown in Figure $11 \mathrm{~b}$, demonstrate the high stability of the microstructured coated Si photoanode that could be operated for a duration of more than 1 hour with no sign of degradation and a constant photocurrent in $1 \mathrm{M} \mathrm{KOH}$. To sum up, these electrochemical results clearly demonstrate that the use of the antireflective macroporous surfaces as photoanodes leads to improvement in terms of photocurrent and overpotential with respect to planar surfaces. In addition, the $\mathrm{TiO}_{2}$ conformal layer provides an efficient protection against etching and photocorrosion.

\section{CONCLUSION}

We have presented a simple and fast two-step wet process, requiring less than 30 min to microstructure $n$-type Si. This method consists in pre-structuring the flat Si by photoelectrochemical etching and then etching the surface in an alkaline solution, which generates arrays of random macropores. It is shown these structures give light-trapping properties to the silicon surface. Using ALD, the antireflective surfaces are coated with nanometer-thick conformal layers of polycrystalline anatase $\mathrm{TiO}_{2}$ layers that further improved the wettability and the light absorption of the porous surfaces. These $\mathrm{TiO}_{2}$-protected $\mathrm{Si}$ microstructured surfaces were highly stable in strongly alkaline solutions and could be used as photoanode for a prolonged time under simulated sunlight. Such photoanode surfaces showed $50 \%$ photocurrent enhancements and $\sim 400 \mathrm{mV}$ negative shift of onset potential without any co-catalysts, demonstrating their high potential for solar energy conversion applications. We 
think that this report opens a way for further research on this type of Si microstructures and we are confident that higher performances will soon be obtained by optimizing the Si

microstructures, the $\mathrm{TiO}_{2}$ layer and decorating these arrays with affordable co-catalysts.

\section{ASSOCIATED CONTENT}

Supporting Information. Additional SEM pictures of the macroporous Si, Evolution of the thickness of the $\mathrm{TiO}_{2}$ layers with the number of ALD cycles, EDX spectrum of the $\mathrm{TiO}_{2}$-coated porous Si, FTIR spectra of the macroporous Si surface, and total, diffuse and the specular reflectance of the surface at various stages of the surface structuring. This material is available free of charge via the Internet at http://pubs.acs.org.

\section{AUTHOR INFORMATION}

\section{Corresponding Authors}

*gabriel.loget@univ-rennes1.fr; lionel.santinacci@univ-amu.fr

\section{Author Contributions}

The manuscript was written through contributions of all authors. All authors have given approval to the final version of the manuscript. 


\section{ACKNOWLEDGMENT}

Dr. F. Tessier and Dr. F. Cheviré (University of Rennes 1) are acknowledged for their help with

the optical measurements. D. Paris (University of Rennes 1) is acknowledged for fabricating the etching cell and Dr. Ahmad Fahs (University of Toulon) is acknowledged for EDS

measurements. M. Barr and M. Diouf are indebted to the Conseil Régional Provence-Alpes-Côte d'Azur, the CNRS and Encapsulix SAS for the PhD grants.

\section{REFERENCES}

(1) Lewis, N. S.; Nocera, D. G. Powering the Planet: Chemical Challenges in Solar Energy Utilization. Proc. Natl. Acad. Sci. 2006, 103 (43 ), 15729-15735.

(2) Pinaud, B. A.; Benck, J. D.; Seitz, L. C.; Forman, A. J.; Chen, Z.; Deutsch, T. G.; James, B. D.; Baum, K. N.; Baum, G. N.; Ardo, S.; Wang, H.; Miller, E.; Jaramillo, T. F. Technical and Economic Feasibility of Centralized Facilities for Solar Hydrogen Production via Photocatalysis and Photoelectrochemistry. Energy Environ. Sci. 2013, 6 (7), 1983.

(3) Prévot, M. S.; Sivula, K. Photoelectrochemical Tandem Cells for Solar Water Splitting. J. Phys. Chem. C 2013, 117 (35), 17879-17893.

(4) Sivula, K.; van de Krol, R. Semiconducting Materials for Photoelectrochemical Energy Conversion. Nat.Rev. Mater. 2016, 1 (2), 15010.

(5) Fujishima, A.; Honda, K. Electrochemical Photolysis of Water at a Semiconductor Electrode. Nature 1972, 238 (5358), 37-38.

(6) Walter, M. G.; Warren, E. L.; McKone, J. R.; Boettcher, S. W.; Mi, Q.; Santori, E. A.; Lewis, N. S. Solar Water Splitting Cells. Chem. Rev. 2010, 110 (11), 6446-6473.

(7) Osterloh, F. E. Inorganic Nanostructures for Photoelectrochemical and Photocatalytic Water Splitting. Chem. Soc. Rev. 2013, 42 (6), 2294-2320.

(8) Kang, D.; Kim, T. W.; Kubota, S. R.; Cardiel, A. C.; Cha, H. G.; Choi, K.-S. Electrochemical Synthesis of Photoelectrodes and Catalysts for Use in Solar Water Splitting. Chem. Rev. 2015, 115 (23), 12839-12887.

(9) Sun, K.; Shen, S.; Liang, Y.; Burrows, P. E.; Mao, S. S.; Wang, D. Enabling Silicon for Solar-Fuel Production. Chem. Rev. 2014, 114 (17), 8662-8719.

(10) Kenney, M. J.; Gong, M.; Li, Y.; Wu, J. Z.; Feng, J.; Lanza, M.; Dai, H. HighPerformance Silicon Photoanodes Passivated with Ultrathin Nickel Films for Water 
Oxidation. Science 2013, 342 (6160), 836-840.

(11) Hwang, Y. J.; Boukai, A.; Yang, P. High Density N-Si/n-TiO2 Core/Shell Nanowire Arrays with Enhanced. Nano Lett. 2009, 9 (1), 410-415.

(12) Chen, Y. W.; Prange, J. D.; Dühnen, S.; Park, Y.; Gunji, M.; Chidsey, C. E. D.; McIntyre, P. C. Atomic Layer-Deposited Tunnel Oxide Stabilizes Silicon Photoanodes for Water Oxidation. Nat. Mater. 2011, 10 (7), 539-544.

(13) Ao, X.; Tong, X.; Sik Kim, D.; Zhang, L.; Knez, M.; Müller, F.; He, S.; Schmidt, V. Black Silicon with Controllable Macropore Array for Enhanced Photoelectrochemical Performance. Appl. Phys. Lett. 2012, 101 (11), 111901.

(14) Hu, S.; Shaner, M. R.; Beardslee, J. A.; Lichterman, M.; Brunschwig, B. S.; Lewis, N. S. Amorphous TiO2 Coatings Stabilize Si, GaAs, and GaP Photoanodes for Efficient Water Oxidation. Science 2014, 344 (6187), 1005-1009.

(15) Lin, Y.; Battaglia, C.; Boccard, M.; Hettick, M.; Yu, Z.; Ballif, C.; Ager, J. W.; Javey, A. Amorphous Si Thin Film Based Photocathodes with High Photovoltage for Efficient Hydrogen Production. Nano Lett. 2013, 13 (11), 5615-5618.

(16) Wang, T.; Luo, Z.; Li, C.; Gong, J. Controllable Fabrication of Nanostructured Materials for Photoelectrochemical Water Splitting via Atomic Layer Deposition. Chem. Soc. Rev. 2014, 43 (22), 7469-7484.

(17) Santinacci, L. ALD for Photoelectrochemical Water Splitting. In Atomic layer deposition in energy conversion applications; Bachmann, J., Ed.; Wiley-VCH Verlag GmbH \& Co. KGaA: Weinheim, 2016.

(18) Barr, M. K. S.; Assaud, L.; Wu, Y.; Laffon, C.; Parent, P.; Bachmann, J.; Santinacci, L. Engineering a Three-Dimensional, Photoelectrochemically Active P-NiO/i-Sb2S3 Junction by Atomic Layer Deposition. Electrochim. Acta 2015, 179, 504-511.

(19) Hill, J. C.; Landers, A. T.; Switzer, J. A. An Electrodeposited Inhomogeneous MetalInsulator-Semiconductor Junction for Efficient Photoelectrochemical Water Oxidation. Nat Mater 2015, 14 (11), 1150-1155.

(20) Ahn, H. S.; Bard, A. J. Single-Nanoparticle Collision Events: Tunneling Electron Transfer on a Titanium Dioxide Passivated N-Silicon Electrode. Angew. Chem. Int. Ed. 2015, 54 (46), 13753-13757.

(21) Boettcher, S. W.; Warren, E. L.; Putnam, M. C.; Santori, E. A.; Turner-Evans, D.; Kelzenberg, M. D.; Walter, M. G.; McKone, J. R.; Brunschwig, B. S.; Atwater, H. A.; Lewis, N. S. Photoelectrochemical Hydrogen Evolution Using Si Microwire Arrays. J. Am. Chem. Soc. 2011, 133 (5), 1216-1219.

(22) Liu, X.; Coxon, P. R.; Peters, M.; Hoex, B.; Cole, J. M.; Fray, D. J. Black Silicon: Fabrication Methods, Properties and Solar Energy Applications. Energy Environ. Sci. 
2014, 7 (10), 3223-3263.

(23) Rey, B. M.; Elnathan, R.; Ditcovski, R.; Geisel, K.; Zanini, M.; Fernandez-Rodriguez, M.A.; Naik, V. V; Frutiger, A.; Richtering, W.; Ellenbogen, T.; Voelcker, N. H.; Isa, L. Fully Tunable Silicon Nanowire Arrays Fabricated by Soft Nanoparticle Templating. Nano Lett. 2016, 16 (1), 157-163.

(24) Mavrokefalos, A.; Han, S. E.; Yerci, S.; Branham, M. S.; Chen, G. Efficient Light Trapping in Inverted Nanopyramid Thin Crystalline Silicon Membranes for Solar Cell Applications. Nano Lett. 2012, 12 (6), 2792-2796.

(25) Zhu, J.; Yu, Z.; Burkhard, G. F.; Hsu, C.; Connor, S. T.; Xu, Y.; Wang, Q.; McGehee, M.; Fan, S.; Cui, Y. Optical Absorption Enhancement in Amorphous Silicon Nanowire and Nanocone Arrays. Nano Lett. 2009, 9 (1), 279-282.

(26) Wu, C.; Crouch, C. H.; Zhao, L.; Carey, J. E.; Younkin, R.; Levinson, J. A.; Mazur, E.; Farrell, R. M.; Gothoskar, P.; Karger, A. Near-Unity below-Band-Gap Absorption by Microstructured Silicon. App. Phys. Lett. 2001, 78 (13), 1850.

(27) Langner, A.; Müller, F.; Gösele, U. Molecular- and Nano-Tubes. In Molecular and Nanotubes; Hayden, O., Nielsch, K., Eds.; Springer US: Boston, MA, 2011; pp 431-460.

(28) Ding, Q.; Zhai, J.; Cabán-Acevedo, M.; Shearer, M. J.; Li, L.; Chang, H.; Tsai, M.; Ma, D.; Zhang, X.; Hamers, R. J.; He, J.-H.; Jin, S. Designing Efficient Solar-Driven Hydrogen Evolution Photocathodes Using Semitransparent MoQ X Cl Y (Q = S, Se) Catalysts on Si Micropyramids. Adv. Mater. 2015, 27 (41), 6511-6518.

(29) Oh, J.; Deutsch, T. G.; Yuan, H.; Branz, H. M. Nanoporous Black Silicon Photocathode for H2 Production by Photoelectrochemical Water Splitting. Energy Environ. Sci. 2011, 4 (5), 1690.

(30) Oh, I.; Kye, J.; Hwang, S. Enhanced Photoelectrochemical Hydrogen Production from Silicon Nanowire Array Photocathode. Nano Lett. 2012, 12 (1), 298-302.

(31) Huang, Z.; Geyer, N.; Werner, P.; de Boor, J.; Gösele, U. Metal-Assisted Chemical Etching of Silicon: A Review. Adv. Mater. 2011, 23 (2), 285-308.

(32) Li, X.; Xiao, Y.; Bang, J. H.; Lausch, D.; Meyer, S.; Miclea, P.-T.; Jung, J.-Y.; Schweizer, S. L.; Lee, J.-H.; Wehrspohn, R. B. Upgraded Silicon Nanowires by Metal-Assisted Etching of Metallurgical Silicon: A New Route to Nanostructured Solar-Grade Silicon. Adv. Mater. 2013, 25 (23), 3187-3191.

(33) Santinacci, L.; Gonçalves, A.-M.; Simon, N.; Etcheberry, A. Electrochemical and Optical Characterizations of Anodic Porous N-InP(100) Layers. Electrochim. Acta 2010, 56 (2), 878-888.

(34) Aghaee, M.; Maydannik, P. S.; Johansson, P.; Kuusipalo, J.; Creatore, M.; Homola, T.; Cameron, D. C. Low Temperature Temporal and Spatial Atomic Layer Deposition of 
TiO2 Films. J. Vac. Sci. Technol. A Vacuum, Surfaces, Film. 2015, 33 (4), 041512.

(35) Lehmann, V. Formation Mechanism and Properties of Electrochemically Etched Trenches in N-Type Silicon. J. Electrochem. Soc. 1990, 137 (2), 653.

(36) Albu-Yaron, A.; Bastide, S.; Maurice, J. L.; Lévy-Clément, C. Morphology of Porous NType Silicon Obtained by Photoelectrochemical Etching II. J. Lumin. 1993, 57 (1-6), 6771.

(37) Lévy-Clément, C. Morphology of Porous N-Type Silicon Obtained by Photoelectrochemical Etching. J. Electrochem. Soc. 1994, 141 (4), 958.

(38) Zhang, X. G. Electrochemistry of Silicon and Its Oxide; Kluwer Academic Publishers: Boston, 2004.

(39) Bell, T. E.; Gennissen, P. T. J.; DeMunter, D.; Kuhl, M. Porous Silicon as a Sacrificial Material. J. Micromechanics Microengineering 1996, 6 (4), 361-369.

(40) Weisse, J. M.; Lee, C. H.; Kim, D. R.; Cai, L.; Rao, P. M.; Zheng, X. Electroassisted Transfer of Vertical Silicon Wire Arrays Using a Sacrificial Porous Silicon Layer. Nano Lett. 2013, 13 (9), 4362-4368.

(41) Sailor, M. J. Preparation of Micro-, Meso-, and Macro-Porous Silicon Layers. In Porous Silicon in Practice; Wiley-VCH Verlag GmbH \& Co. KGaA, 2011; pp 43-76.

(42) Bressers, P.; Kelly, J. J.; Gardeniers, J. G. E.; Elwenspoek, M. Surface Morphology of PType (100)silicon Etched in Aqueous Alkaline Solution. J. Electrochem. Soc. 1996, 143 (5), 1744-1750.

(43) Chen, Y. W.; Prange, J. D.; Dühnen, S.; Park, Y.; Gunji, M.; Chidsey, C. E. D.; McIntyre, P. C. Atomic Layer-Deposited Tunnel Oxide Stabilizes Silicon Photoanodes for Water Oxidation. Nat. Mater. 2011, 10 (7), 539-544.

(44) Ritala, M.; Leskela, M.; Niinisto, L.; Haussalo, P. Titanium Isopropoxide as a Precursor in Atomic Layer Epitaxy of Titanium Dioxide Thin Films. Chem. Mater. 1993, 5 (8), 11741181 .

(45) Aarik, J.; Aidla, A.; Uustare, T.; Ritala, M.; Leskelä, M. Titanium Isopropoxide as a Precursor for Atomic Layer Deposition: Characterization of Titanium Dioxide Growth Process. Appl. Surf. Sci. 2000, 161 (3-4), 385-395.

(46) Ritala, M.; Leskelä, M.; Nykänen, E.; Soininen, P.; Niinistö, L. Growth of Titanium Dioxide Thin Films by Atomic Layer Epitaxy. Thin Solid Films 1993, 225 (1-2), 288-295.

(47) Xie, Q.; Musschoot, J.; Deduytsche, D.; Van Meirhaeghe, R. L.; Detavernier, C.; Van den Berghe, S.; Jiang, Y.-L.; Ru, G.-P.; Li, B.-Z.; Qu, X.-P. Growth Kinetics and Crystallization Behavior of TiO2 Films Prepared by Plasma Enhanced Atomic Layer Deposition. J. Electrochem. Soc. 2008, 155 (9), H688. 
(48) McDowell, M. T.; Lichterman, M. F.; Carim, A. I.; Liu, R.; Hu, S.; Brunschwig, B. S.; Lewis, N. S. The Influence of Structure and Processing on the Behavior of $\mathrm{TiO} 2$ Protective Layers for Stabilization of N-Si/TiO2/Ni Photoanodes for Water Oxidation. ACS Appl. Mater. Interfaces 2015, 7 (28), 15189-15199.

(49) Roy, P.; Berger, S.; Schmuki, P. TiO2 Nanotubes: Synthesis and Applications. Angew. Chem. Int. Ed. 2011, 50 (13), 2904-2939.

(50) Coffinier, Y.; Piret, G.; Das, M. R.; Boukherroub, R. Effect of Surface Roughness and Chemical Composition on the Wetting Properties of Silicon-Based Substrates. C. R. Chim. 2013, $16(1), 65-72$.

(51) Piret, G.; Galopin, E.; Coffinier, Y.; Boukherroub, R.; Legrand, D.; Slomianny, C. Culture of Mammalian Cells on Patterned Superhydrophilic/superhydrophobic Silicon Nanowire Arrays. Soft Matter 2011, 7 (18), 8642.

(52) Chen, H.-Y.; Lu, H.-L.; Ren, Q.-H.; Zhang, Y.; Yang, X.-F.; Ding, S.-J.; Zhang, D. W. Enhanced Photovoltaic Performance of Inverted Pyramid-Based Nanostructured BlackSilicon Solar Cells Passivated by an Atomic-Layer-Deposited Al 2 O 3 Layer. Nanoscale 2015, 7 (37), 15142-15148.

(53) Shi, J.; Hara, Y.; Sun, C.; Anderson, M. A.; Wang, X. Three-Dimensional High-Density Hierarchical Nanowire Architecture for High-Performance Photoelectrochemical Electrodes. Nano Lett. 2011, 11 (8), 3413-3419.

(54) Shaner, M. R.; McDowell, M. T.; Pien, A.; Atwater, H. A.; Lewis, N. S. Si/TiO2 TandemJunction Microwire Arrays for Unassisted Solar-Driven Water Splitting. J. Electrochem. Soc. 2016, 163 (5), H261-H264. 
Table of Contents Graphic

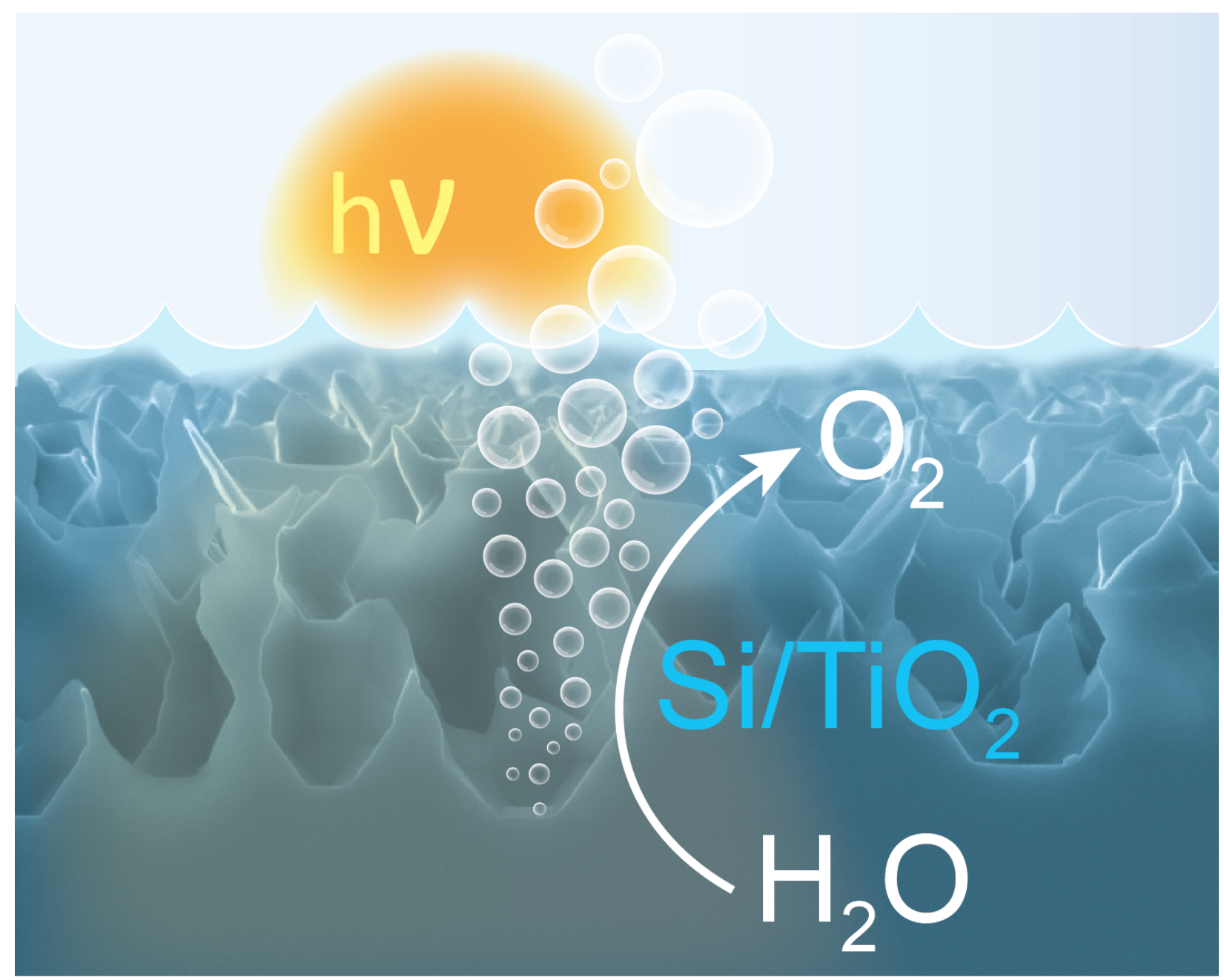

